\title{
In search of an Instructional Material Design Model to Support the Implementation of IQF Oriented Curriculum at HEIs
}

\author{
Konder Manurung \\ Universitas Tadulako \\ Palu, Indonesia \\ kmanurung@hotmail.com
}

\begin{abstract}
The implementation of newly developed or revitalized curriculum requires enhancement of the previously implemented instructional packages to perfectly address the formulated instructional goal. This paper aims at searching and proposing a model of instructional material design to support the upcoming implementation of the Indonesian Qualification Framework (IQF) oriented curriculum at Higher Education Institutions (HEIs) level in Indonesia. Secondary sources library research method was applied to find out secondary sources in Instructional Design (ID) models that have been used in designing and developing instructional materials in education and training program. The paper reviewed the IQF and the ID models and discussed their implementation. The paper is ended up by proposing a tentative model in the design of instructional materials that underpin the implementation of the IQF oriented curriculum at universities in Indonesia.
\end{abstract}

Keywords-Curriculum; instructional material; instructional design; Indonesia Qualification Framework; higher education institutions

\section{INTRODUCTION}

Implementation of newly developed, revitalized or changed curriculum requires enhancement of the previously implemented instructional packages to perfectly address the formulated instructional goal. The enhancement of the instructional materials is needed so that they fulfill needs of learners and the society that is stated in the instructional goal in the curriculum level which is translated into more specific objectives that are generally called as instructional objectives. The instructional objectives are generally formulated at school level in the school syllabus so the planned and prepared topics of instructional materials are contextual and measurable which means learners are able to do what they are expected to do as the results of the instruction.

\section{A. Indonesian Qualification Framework}

Indonesian education system through Ministry of Education and Culture and Ministry of Research, Technology and Higher Education have developed and revitalized curricula for several times in order to meet needs of advancement in science and technology, social and politic, economic, and culture. The latest curriculum which is implemented by the Ministry of Education and Culture is '2013 curriculum' from elementary school to senior high school, while at the higher education levels (HEIs) through Ministry of Research, Technology and Higher Education intends to implement upcoming IQF oriented
Curriculum. The implementation of IQF oriented curriculum is based on the Presidential Decree Number 8 in 2012 [1]. As it is stated in [1] IQF is a framework of leveling competency qualification that enables equalization, harmonization, and integration among formal education, vocational training and education, and working experiences in rewarding or recognizing work competency in line with the job structure in each sector.

Reference [1] classifies the qualification into nine levels of outcomes and divided into five categories; the first category is from level 1 to level 5 for elementary to high school levels, the second category is level 6 for undergraduate and Diploma 4, the third category is level 7 for professional education, the fourth category is level 8 for graduate programs for master's degree and specialization, and the last category is level 9 for postgraduate program for doctorate degree. Through the IQF oriented curriculum, the Indonesian government intends to standardize education output quality in Indonesian education system. Reference [2] highlighted that qualification system include all aspects of country's activity that result in the recognition of learning. The establishment of IQF which is also called as National Qualification Framework (NQF) is expected to respond the establishment of ASEAN Economic Community (AEC) where qualifications across ASEAN member countries can be compared [3]

\section{B. Instructional Design}

Instructional design (ID) is a term used in education and training program to indicate the development and implementation of each instructional step from the pre-teaching activity to evaluation in teaching-learning process. Some experts in educational technology [4] - [10] argued that ID is needed to effectively achieve the developed goals of education and training program. Reference [4] viewed ID as the implementation of teaching and learning theories in facilitating someone's learning [5] and [9] proposed systemic approach in the development of instructional materials, [6] formulate the ID in relation to improvement of working quality and organization, [7] argued that the ID provide learners with assistance in learning process, [8] proposed that the implementation of ID is related in to management aspect, and [10] suggested that ID as systemic series of procedures to develop consistent education and training program.

Education and training program needs achievable and measurable instructional objectives. Ref. [11] highlighted that 
learners, objectives, methods, and evaluation are the main components of ID. Furthermore, [12], [13], [14], and [15] suggested that the formulation of the instructional goal stated in curriculum is generally based on the results of the needs analysis. Reference [12] highlighted that learning goal may be derived from a number of sources, including task analysis, learner data, ministry of education specification, and so on. Reference [13] argued that need analysis is generally done for various users in education system particularly in developing new curriculum and revitalizing implemented curriculum, [14] evaluate instructional materials by applying ID evaluation instrument, and [15] applied analysis phase of ADDIE to develop instructional materials. More importantly, [16] argue that the design process of curriculum is begun by identifying the expected results then move back to instruction development, and [17], highlighted that new curriculum and teaching strategies ask the students not only to master factual information but also learn to apply that information by reasoning and solving novel problems. The above arguments imply that the results of the need analysis guide curriculum designers to clearly formulate instructional goal so that output and outcome of the designed and developed curriculum might be perfectly attained by providing learners with appropriate instructional materials designed and developed based on stated goal.

Reference [5] and [9] indicated the instructional goal determine what learners to be able to do after the completion of the teaching and learning process. Reference [5] and [9] further highlighted that the ability to determine the instructional goal leads to well developed instructional packages consisting of instructional materials, assessments, and course management information. In addition, [18] and [19] revealed the advantages of interest based and real-life instructional materials to motivate learners to learn and to improve the learners' achievement. Regarding the instructional packages, highlighted by [5] and [9], the problem to be addressed in this paper is that what is the suitable instructional material design model that supports the upcoming implementation of IQF oriented curriculum at HEIs in Indonesia.

\section{METHOD}

Since the objective of the study was to propose an alternative instructional material design model to support the upcoming implementation of IQF oriented curriculum at HEIs in Indonesia, the study applied secondary sources library method [20] which involved identifying and locating sources that contain information needed to satisfy the objective of the study. Therefore, available references in IQF and ID models were explored and reviewed.

\section{RESULTS AND DISCUSSION}

As the study aims at proposing an instructional material design model to support the upcoming implementation of IQF oriented curriculum, the findings are divided into two sections, the first is the IQF, and the second is the instructional design models.

\section{A. Indonesian Qualification Framework}

Skillful human resources to compete globally are highly required due to rapid advancement in science, information and technology, and job market global competition. The Indonesian government, through National Education Minister and Technology, Research, and Higher Education Minister, responded the globalization era by reforming and revitalizing curriculum in the education system. Ministry of National Education implemented 2013 Curriculum and Ministry of Research, Technology and Higher Education has socialized and planned to immediately implement IQF oriented curriculum in which the recognition of prior learning, current competence, training, and educations are accommodated in the statement of workforce qualification and competencies.

The implementation of the 2013 curriculum from elementary school to senior high schools and the IQF oriented curriculum at HEIs in Indonesia is based on [1]. The IQF is a reflection of human resources quality in Indonesia [1]. Masehat (2016)[21] quoted that at the national level, IQF acts as a neutral reference that can equalize learning outcomes resulted from formal or training/ nonformal education, as well as learning outcomes acquired through job experiences. Reference [21] further highlighted that IQF Descriptors of each level reflects the learning outcomes that can be demonstrated by a person after completing programs or experiences in the following pathways, education, training, on the job experience, and self-learning. Reference [1] stated that learning outcomes are internalization and accumulation of science, knowledge, know-how, skills, and affective aspects acquired through education, training, job experience or self-learning processes. The establishment of the IQF or National Qualification Framework (NQF) is to enable the competencies of HEIs graduates to be comparable with those graduates from ASEAN HEIs members [3].

IQF level is divided into nine and they are divided into three broad qualification categories; operator (level 1-3), technician/analyst (Level 4-6), and expert (level 7-9). Based on [1] and [2] in addition to each level of competencies, each level is subject to the general competencies such as moral, ethics and good personality in doing job at workplace, religion of trust in God The Almighty, able to cooperate, empathy on work environment, able to honor diversity of culture and beliefs, religion, and do not act against the law [1].

HEIs level is divided into technician/analyst and expert where HEIs, undergraduate program, and graduate program, is categorized in level 6-9. For the purpose of the current study, the descriptors of level 6 which is classified as undergraduate based on [1] and [21] are presented as follows;

Level 6 is able to; 1) apply own expertise and utilize science, technology, and art in the field of expertise to solve the problem and to adapt to the situation faced, 2) master general theoretical concepts in certain area of knowledge and special part of theoretical concepts in the field of knowledge in depth, and is able to formulate procedural problem solving, 3) take appropriate decisions based on information and data analysis, and 4) provide guidance in selecting a variety of alternative solutions individually and group, are responsible for own work and can be given responsibility for the achievement of organizational work. 
The descriptors indicate that HEIs in Indonesia have to establish and set up graduates' profile, particularly at the department level and consequently design and develop instructional packages accordingly to underpin the process in preparing and producing outputs and outcomes as intended by the descriptors. HEIs graduates are expected to be able to apply and utilize what they have learnt, have sufficient knowledge to overcome faced problems, to draw data analysis based decision, and to be responsible in the achievement of an organization where they work.

\section{B. ID Model}

An ID model provides the possibility to effectively prepare instructional process and instructional materials to meet needs of learners. It has long been used in teaching and learning process in education and training. The ID model is developed by experts in education due to the advancement of science and technology so that the design model fulfills needs of learners, community, and learners in relation to the community.

There have been some ID models developed in education and training programs, and the models are complementary to each other. For the purpose of the current study, commonly implemented ID models were reviewed including ADDIE Model, Dick \& Carey, Kemp Model, IPDM, and Three-Phase Design Model.

\section{ADDIE model}

Educational technology experts scrutinize and engineer practices and activities in teaching learning process to attract learners' motivation to bring about better instructional outcomes. One of the results of the experts' effort in ID was the establishment of ADDIE model that has long been implemented in the design of instructional materials. The ID-based on ADDIE model has been known by-Analysis, Design, Development, Implementation, and Evaluation [10]. The phases are used as a guide to design and develop instructional packages so that training and instruction can be effectively conducted ([10], [15], and [22]). Each phase of ADDIE is to be completed in the design of instructional materials due to the provision of information from one phase to the next phase.

The ADDIE phase can be described as follows; Phase 1 Analysis; this phase identifies and clarifies instructional problems as the main factor to formulate the instructional goals and objectives; Phase 2 Design; this phase is related to some components that are systematically done so that the first component supports the next one to create an effective output. The components of design phase are learning objectives, assessment instruments, exercises, content, subject matter analysis, lesson planning and media selection which are designed based on the results of phase 1; Phase 3 Development; this phase is related to the role of the designer and developer to create, assemble, review, and revise the content based on the results of phase 2; Phase 4 Implementation; this phase includes development of training procedures for both facilitator and learners, includes the course curriculum, learning outcomes, method of delivery, and testing procedures and for the learners the development of the procedure includes training on teaching aids and registration; Phase 5 Evaluation; this phase consists of formative and summative. The formative evaluation is done in each phase to enable the developer to do revision and the summative evaluation is done to get overall feedback.

\section{Dick and Carey model}

Dick and Carey's model is known as a systematic approach in ID where each component is related to each other. Reference [5], [23] and [9] introduced ID model that consists of nine steps. Step 1 Identify Instructional Goal; this step identifies what learners are expected to be able to do after the instruction; Step 2 Conduct Instructional Analysis; this step brings about information on entry behaviors, prior knowledge of the topic area, attitudes toward content and potential delivery systems, academic motivation, attitude toward the organization [9]; Step 3 Write Performance Objectives; this step specifies what a learner should be able to do after the instruction [9]; Step 4 Develop Assessment Instruments; this step develops evaluation instrument to measure the attainment of the stated instructional objective [9]; Step 5 Develop Instructional Strategy; this step develops instructional strategy includes pre-instructional activities, presentation of information, learner's participation, testing, and follow-through activities [9]; Step 6 Develop and Select Instruction; this step produces draft of instructional materials, assessment, and manuals [9]; Step 7 Design and Conduct Formative Evaluation; this step allows the revision the instruction [9]; Step 8 Revise Instruction; in this step the results of formative evaluation is used to revise the instruction, and Step 9 Design and Conduct Summative Evaluation; although this step is not regarded as part of the ID elements, it is considered important to evaluate instruction [9].

\section{Morrison, Ross, and Kemp model}

Morrison, Ross, and Kemp Model which is also known as Kemp Model are based on continuous cycle in the use of each ID element from planning, design, development to assessment that ensure the creation of effective instruction. Kemp Model was proposed in 1985 and was modified in 1994. The modification was in the addition of two more components (planning support service and separating formative and summative) to indicate that the emphasis is in the process [11] therefore the ID model consists of nine elements.

The nine elements of Kemp model [24] are; 1) Instructional Problems Identification; this element guides the construction of instructional goal for designing instructional program; 2) Learners Characteristics Exploration; this element guides the planning process of the instructional program; 3) Task Analysis; this element guides the choice of knowledge and procedures so that the formulated objective can be effectively attained; 4) Statement of Instructional Objectives; this element guide to specify what the learner must learn and master; 5) Content Sequencing; this element guides to arrange content in a logical order in order to provide effective learning; 6) Instructional Strategies; this element guides the design of creative and innovative strategies to create effective instructional process; 7) Instructional Planning and Development; this element guides the choice and organization of the instructional materials to support instructional activities; 8) Evaluation Instruments Development; this element guides the construction of the evaluation instruments to measure the achievement of the instructional objectives; 9) Resource 
Selection; this element guides the selection of resources to support instruction and learning activities [24] and [11].

\section{IPDM model}

The establishment of ID model is to enable an instruction process to take place effectively. Instructional process is effective if it is supported by other components such as project management, information handling, resource acquisition and allocation, ID project personnel, and facilities [8]. Reference [8] argued that instructional design should teach what to do and how to do.

Reference [4] established IPDM model that consisted of eight development components. They are; 1) Needs analysis; through this component, goals are proposed; 2) Adoption; through this component, innovation is accepted and commitment of resources is obtained; 3) Instructional Design; through this component objectives, strategies, techniques, and media for meeting instructional goals are determined and specified; 4) Production; through this component, elements of the project are constructed; 5) Prototyping; through this component an instructional unit is assembled, pilot tested, respecified, validated, and finalized; 6) Product Installation, through this component, the necessary conditions for effective operation of a new instructional product or process is established; 7) Ongoing Operation; through this component the continuing application of an instructional product and/or procedure is maintained; and 8) Ongoing Instructional Unit Evaluation; through this component data about an ongoing instructional unit to make decisions about future revision are collected and analyzed.

\section{3PD model}

Another ID model that has been used in designing instructional materials is Three Phase Design Model (3PD). This ID model is considered an enhancement to conventional ID model where the model focuses on the creation of function of course delivery components. This ID model has been reported successfully in the implementation of online instructional materials development [25] and [26]. Reference [25] and [26] develop 3PD through a three-step process; develop functionality, evaluate/elaborate/enhance, and maintain.

The development of 3PD intends to build up independent learning where learners minimize the dependent on the developer and educational designer [25]. Therefore the 3PD scrutinize experiences in each phase as follows [25] and [26; Phase I: Prepare Functional Components; this phase guides the creation of the design and development the course material and delivery strategy; Phase II: Evaluate, Elaborate and Enhance; this phase guides the revision of the plan, the evaluation and adjustment of the course elements, the change of the delivery components, and the choice of intended types of collaboration; Phase III: Maintain; this phase guides the course maintenance based on the feedback regarding the delivery method, the design element, and the strategy.

\section{Alternative ID Model}

The most important implication of ID in instruction is the ability to bring together all education elements to bring about better outputs and outcomes. These elements, through ID process, are able to actualize a well-planned process in developing education and training program to provide effective learning activities. Through ID model, the learning activities are perfectly designed, planned and implemented that they attract and increase learners' attention and learning motivation.

The plan to implement IQF oriented curriculum at HEIs in Indonesia requires ID model that can facilitate the implemented curriculum with the qualification level stated in the IQF. The available ID models, for examples ADDIE, Dick and Carey, Kemp, IPDM, and 3PD have been widely used in education and training program. Are these models suitable for the education system and education culture in Indonesia? Those models have provided steps where every component support each other to provide a well design learning packages. However, it is noted that culture, education system, and teaching atmosphere are of great importance to consider.

Instructions at HEIs in Indonesia are mostly highly dependent on the commercially available instructional materials. This kind of materials lead theory-based instruction and consequently expected outcomes are not fully attained. More importantly, this kind of instruction does not challenge learners to be creative and innovative. Instruction delivery system is in general lecture-based and assessment and evaluation is mainly on cognitive domain. Therefore it is suggested that ID model at HEIs can be based on any of those available ID models but it should take into account; 1) Indonesian learners' learning culture, 2) the choice and the development of instructional materials system, 3) current instructional delivery method at HEIs, and 4) implemented assessment and evaluation system due to the fact that educational system and educational culture plays important role in instructional process. The four components have to be analyzed so that HEIs produce qualified outputs that meet the stated criteria in the IQF through well planned instructional packages and in accordance with the defined profile of the department' outputs at HEIs level.

\section{CONCLUSION}

IQF or NQF has determined expertise of graduates at each level of education where graduates of HEIs are classified as Analyst for undergraduate program and Expert for the graduate program. Classification of the graduates at each level needs well plan curriculum in which instructional goals are formulated to meet needs of learners, society, and learners in relation to society. The leveling system in the IQF implies that every instructional goal stated in the implemented curriculum at each level has to produce outcomes based on the graduate's classification so that particular level of education becomes a stepping stone to perfectly achieve the outcomes of the next level. It means that there are instructional packages developed based on the instructional objectives that have been stated in each curriculum in relation to IQF level to ensure that a graduate is ready to enter next education level that meets the qualification 
stated in IQF. It is important to consider that the developed instructional packages are Indonesian cultural friendly first and then regional and international oriented next.

\section{REFERENCES}

[1] Kementerian Hukum dan Perundang Undangan, 2012, President Regulation On Indonesian National Qualification Framework, Jakarta.

[2] P. Silitonga. The exploratory study on national qualification framework of Indonesia and other pioneer implementor countries. International Journal of Information Technology and Business Management, vol. 9 (1), pp.40-46, January 2013.

[3] Dokumen 009, Support to the development of the Indonesian qualifications framework (ACDP - 024) final report. 2015. PT Trans Intra Asia (TIA), Indonesia in association with the Institute of Public Administration of Canada (IPAC), Canada for the Education Sector Analytical and Capacity Development Partnership.

[4] C.M. Reigeluth, Instructional Design; Theories and models, New York. Lawrence Erlbaum Associates, Publ. 1983.

[5] W. Dick, \& L. Carey, The Systematic Design of Instruction (3rd ed.) New York: Harper Collins College Publishers. 1990.

[6] W.J. Rothwell, \& H.C, Kazanas, Mastering the instructional design: A systematic approach. San Francisco, CA. Jossey-Bass Publisher. 1992.

[7] R.M. Gagne, L.J. Brigs, \&W.W. Wager, Principles of instructional design $\left(4^{\text {th }}\right.$ ed.). Fort Worth. Harcourt Brace Jovanovich College Publishers. 1992.

[8] C.G. Gentry, Introduction to instructional development: Process and technique. Belmont, CA: Wadsworth Publishing Company. 1994.

[9] W. Dick, L. Carey, and J.O. Carey, The systematic design of instruction (5th ed.). The United States. Addison-Wesley Educational Publishers Inc. 2001

[10] R. Reiser, \& J. Dempsey, eds., Trends and issues in instructional design and technology. Upper Saddle River, NJ. Merrill-Prentice Hall. 2002.

[11] J.E.Kemp, G.R. Morrison, \& S.V. Ross, Design effective instruction, New York: Macmillan. College Publ. Company. 1994.

[12] D. Nunan, Syllabus Design. Oxford. Oxford University Press. 1988.
[13] J.C. Richards, Curriculum development in language teaching. Cambridge. Cambridge University Press. 2001.

[14] Hashim, Y., Are instructional design elements being used in module writing design? British Journal of Educational Technology, 30(4), 341358, 1999.

[15] N. Prammanee, Applying ADDIE model for research and development: An analysis phase of communicative language of 9 Grad students. Proceedings of the Burapha University International Conference 2016, 28-29 July 2016.

[16] G. Wiggins, and C. McTighe, Understanding by design. Alexandria, VA. Association for Supervision and Curriculum Development. 1998.

[17] K.D. More, Effective instructional strategies from theory to practice. Thousand Oaks California. Sage Publication, Inc. 2005.

[18] K. Manurung, Improving the Speaking Skill Using Reading Contextual Internet-based Instructional Materials in an EFL Class in Indonesia. Procedia. Social and Behavioral Sciences, 176 (20): 571-579, 2015.

[19] K. Manurung, Designing instructional materials to improve EFL learners achievement. International Journal of English Language, Literature and Humanities, V (2): 115-130, February 2017.

[20] J.D. Brown, \& T.S. Rodgers, Doing second language research. Oxford. Oxford University Press. 2002.

[21] K. Masehat, Updates on Indonesia qualification framework (IQF) development. Regional Skills Technical Working Group Meeting. Bangkok, Thailand, 3 May 2016.

[22] Wikipedia. ADDIE Model. Document courtesy of Wikipedia.org. http://www.instructionaldesign.org/models/addie.html Retrieved on 26 Maret 2017

[23] W. Dick, \& L. Carey, The systematic design of instruction $\left(4^{\text {th }}\right.$ ed.). New York: Harper Collins College Publishers. 1996.

[24] J.E. Kemp, The instructional design process. New York: Haper and Row. 1985.

[25] R. Sims, G. Dobbs, \& T. Hand, Enhancing quality in online learning: Scaffolding design and planning through proactive evaluation. Distance Education, 23(2), 135-148, 2002.

[26] R. Sims, \& D. Jones, Where practice informs theory: Reshaping instructional design for academic communities of practice in online teaching and learning. Information Technology, Education and Society, 4(1), 3-20. 2003. 